\title{
CULTURA ESCRITA, LITERATURA Y POLÍTICA EN EL PARTIDO OBRERO DE CÓRDOBA
}

\author{
Sol Anahí VIÑOLO ${ }^{1}$
}

Resumen: La cultura escrita ha tenido un lugar muy importante en la historia del Partido Obrero y es un elemento fundante, constituyente y vital de toda su actividad política en la actualidad. A partir del registro documental y el trabajo de campo realizado en el Partido Obrero entre 2014 y 2015 en Córdoba, se busca dar cuenta del lugar que la cultura escrita y la literatura, en particular, tienen en la construcción de la organización trotskista argentina. Así como reflexionar sobre las potencialidades de la antropología para estudiar la literatura y más específicamente la relación entre la literatura y la política.

Palabras clave: cultura escrita, literatura, política, Partido Obrero, Córdoba.

Abstract: Written culture has had a very important place in the history of the Partido Obrero and is a fundamental, constituent and vital element of all its political activity today. Based on the documentary record and the field work carried out in the Partido Obrero between 2014 and 2015 in Córdoba, it seeks to account for the place that written culture and literature, in particular, have in the construction of the Argentine Trotskyist organization. As well as reflect on the potential of anthropology to study literature and more specifically the relationship between literature and politics.

Keywords: Written culture, literature, politics, Partido Obrero, Córdoba.

Résumé: La culture écrite a eu une place très importante dans l'histoire du Partido Obrero et est aujourd'hui un élément fondamental, constituant et vital de toute son activité politique. Sur la base du dossier documentaire et du travail de terrain réalisé dans le Partido Obrero entre 2014 et 2015 à Córdoba, il cherche à rendre compte de la place que

\footnotetext{
${ }^{1}$ Licenciada en Antropología, Universidad Nacional de Córdoba. Doctoranda en Ciencias Antropológicas de la Facultad de Filosofía y Humanidades de la UNC. Becaria de la Secretaría de Ciencia y Tecnología de la UNC; Instituto de Antropología de Córdoba.

sol.anahi@outlook.com
}

Fecha de recepción del artículo: Diciembre 2020

Fecha de evaluación:Marzo 2021 
la culture et la littérature écrites, en particulier, ont dans la construction de l'organisation trotskyste argentine. En plus de réfléchir sur le potentiel de l'anthropologie pour étudier la littérature et plus spécifiquement la relation entre littérature et politique.

Mots clés: Culture écrite, littérature, politique, Partido Obrero, Córdoba.

\section{Introducción}

El objetivo de este artículo es reflexionar sobre las potencialidades de la antropología para estudiar la literatura y más específicamente la relación entre la literatura y la política, como una forma, entre otras, del "afuera" del lenguaje -tópico, en general, estudiado por otras disciplinas como la filosofía y la crítica literaria-, a partir de la experiencia de mi investigación etnográfica realizada en los años 2014 y 2015 en el Partido Obrero de Córdoba. Para ello, parto de la materialidad de la literatura, en su presencia y circulación, inserta en un conjunto de prácticas determinadas, considerándola, a su vez, dentro de una categoría más amplia de heterogéneos indisociables y márgenes difusos que es la cultura escrita; así como de las concepciones de la literatura que inciden en mayor o menor medida en el vínculo literatura/política hacia dentro de esta comunidad. Puesto así, no sería, precisamente, la literatura el objeto de estudio (que implicaría la existencia de un sistema conceptual de nociones que hiciera de metalenguaje) sino, más bien, la presencia de la literatura en una comunidad en particular, que es el Partido Obrero, focalizando en la provincia de Córdoba pero reconociendo en la ciudad de Buenos Aires un centro neurálgico de la actividad partidaria. La elección de un partido político, se debe a que decidí centrar el análisis en un campo donde la "política" fuese parte constitutiva de los sujetos y que definiera, de alguna forma, una pertenencia colectiva y una trayectoria común más o menos significativa (pensando en tiempo de participación o "militancia"). La elección del Partido Obrero fue un tanto azarosa, pero tuvo como premisa el hecho de que se trata de un partido con una producción textual prolífica.

Las tesis fundamentales que se propusieron al principio de la investigación fueron, por un lado, que las especificidades del entre literatura y política, adquieren ciertos rasgos compartidos dentro de una misma comunidad por las trayectorias y definiciones de adscripciones comunes (individuales y colectivas) que establecen los márgenes de la comunidad y la pertenencia a ésta. Y, por el otro, que la literatura, es parte de un conjunto más amplio, la cultura escrita, que es necesario investigar en su conjunto para comprender el lugar y la función de la literatura en particular.

Para dimensionar el lugar clave de la cultura escrita en el Partido Obrero, que pude percibir etnográficamente desde el primer día que pise el local partidario con el olor a tinta fresca y el tac, tac, tac, tac, cada medio segundo, que se escuchaba de fondo por cada emisión de impresos en la foto-duplicadora, resulta indispensable considerar la configuración de una "izquierda" internacional y un "ethos" socialista que se erigió sobre la cultura escrita partidaria y que se consolidó con la experiencia del octubre rojo. Pensar a la prensa política en su condición de intermediaria como agente configurador de ciertos discursos y prácticas, nos permite entender, por ejemplo, la urgencia de Lenin en 1900 por publicar un periódico nacional que llegue a toda Rusia y que logre organizar colectivamente a todos los grupos socialdemócratas dispersos. Este proyecto, que tomó forma en diciembre de ese año cuando se publicó por primera vez Iskra (La chispa) desde Alemania, buscó combinar su rol propagandístico y de agitador entre las masas, con el de organizador del partido. Sin embargo, un siglo después, habiendo sido desplazada la prensa impresa como vehículo privilegiado de las ideas en la sociedades en general, las organizaciones que se reivindican socialistas continúan otorgándole un rol destacado a la cultura impresa, alrededor de la cual rondan prácticas y hábitos cotidianos de militancia. 
Esta situación es la que lleva a Angenot a decir, por ejemplo, que el objeto central de la historia socialista debiera residir en el estudio de su propaganda puesto que es ella la que organiza las acciones de una organización mediante la unificación de un discurso y un objetivo común (Angenot, 2010). Un ejemplo de esto es la fuerte relación entre prensa y partido que Régis Debray (2001) destaca en el caso de Francia, donde no existieron partidos obreros hasta la aparición de la prensa. Esto mismo puede extenderse al caso argentino, como se observa con el surgimiento del Partido Socialista Obrero Argentino tras la fundación de El Obrero en 1890 (Martínez Mazzola, 2005), y con la fundación de la misma Política Obrera (actualmente Partido Obrero) a través de la aparición de su primera publicación, homónima a la organización, que llevó el lema "por un partido obrero", que acompañó a las distintos formatos de la publicación hasta la actualidad, medio siglo más tarde. El abordaje "mediológico" de la prensa socialista que propone Debray (2001), que implica considerar el conjunto de las formas y los procesos materiales a través de los cuales las ideas y discursos son transmitidos, podría ser útil para analizar el caso del PO, en donde la cultura escrita -y la prensa en particular-, han tenido un lugar muy extenso en la historia de la organización y es un elemento fundante, constituyente y vital de toda su actividad política en la actualidad.

La cultura escrita, entendida en un sentido amplio como el conjunto de prácticas que componen el mundo de la lectura y la escritura, es sin duda un asunto de posibilidades imperecederas de reflexión, más aún si es abordado desde realidades geográficas y temáticas concretas como lo hacen Chartier (2006), Darnton (2003), Goody (1996), y Burke (1993), entre otros, y cada uno a su manera. Este tipo de estudios, ya de larga tradición en Europa y el mundo anglosajón, se han multiplicado en la última década en Argentina y Latinoamérica, ramificándose en la transdisciplinariedad para abarcar todo un espectro de investigaciones que enfatizan las particularidades locales. Este artículo, basado en el trabajo de campo que realicé en el PO durante 2014 y 2015 en la ciudad de Córdoba, busca ser un aporte a estos estudios.

\section{Cultura escrita en el PO}

"Sin escritura no hay posición política, por eso digo que militar es escribir. La manera de construir un partido es sacar un periódico. Un partido es su periódico, una publicación por escrito de sus posiciones. Sin una posición por escrito no hay intervención en la realidad"

Entrevista Franco Boczkowski, 09/2014

En Marzo de 1964, un grupo de jóvenes trotskistas que se separan de Reagrupar (desprendimiento del Movimiento de Izquierda Revolucionario Argentino) fundan Política Obrera (actualmente Partido Obrero), ante la caracterización de la necesidad de que la clase trabajadora debía forjar su propia dirección revolucionaria y que ésta debía llevarla a cabo un partido que se propusiera la toma del poder y la revolución mundial. El lema "por un partido obrero", acompañó desde la primera publicación, homónima a la organización, que con su aparición dio inicio públicamente a la nueva agrupación de la izquierda argentina.

La década del '60 fue una década de enorme radicalización en el ámbito internacional, particularmente en América Latina, donde la revolución cubana del año '59 despertó una renovación del "espíritu" revolucionario de una generación entera, que se tradujo, a su vez, en la Argentina con una especificidad propia. 1959 es también el año de la huelga 
Lisandro de la Torre en Capital Federal que constituye una bisagra de la reacción de la clase obrera peronista frente a la impotencia de la dirección del gobierno de Evita, que ya se había manifestado antes de la huelga, cuando la clase obrera argentina desoye la orden de Perón de votar a Frondizi y votan masivamente en blanco. "Y en ese contexto, surge un grupo de compañeros que hace una valoración de todo eso para concluir en la necesidad de construir una vanguardia consciente que ayude a elaborar toda esa experiencia, un partido capaz de actuar junto a la clase obrera para abrir un rumbo en el movimiento histórico" (Entrevista Pablo Rieznik, 11/2014).

Adscribiendo al trotskismo y convencidos de la tendencia histórica del capitalismo a su debacle, Política Obrera, se funda con la convicción de construir un partido de trabajadores en oposición a dos tendencias dominantes en la izquierda de la época: por un lado, una posición unilateral, en principio anti-staliniana, que proponía la formación de grupos armados o "focos" para crear "desde afuera" la experiencia de las masas y obtener así un desarrollo revolucionario -sosteniendo una polémica enérgica contra esta tendencia "foquista", en defensa de una perspectiva de rebelión popular, como la que ocurriría pocos años más tarde en el Cordobazo-; y, por el otro, la vieja izquierda stalinianista que concebía al peronismo como policlasista y proponía disolverse en su interior. También le criticaban a esta corriente la imposibilidad de llevar a cabo el socialismo en un solo país que sostenía el Partido Comunista; considerando que la revolución socialista era tarea del proletariado internacional. En consecuencia, el PO abordó la tarea de refundar la IV Internacional como nucleamiento de la clase obrera a nivel mundial, conformando la Coordinadora por la Refundación de la Cuarta Internacional (CRCI) que posee su propia publicación, El Obrero Internacional; además de llevar adelante numerosas campañas de solidaridad internacional a lo largo de su historia y dedicar regularmente, en Prensa Obrera, una parte de sus análisis políticos a la situación internacional.

Desde sus mismos orígenes, Política Obrera inicia su militancia en la clase obrera y construye agrupamientos en los principales sindicatos (mecánicos, metalúrgicos, textiles, vidrio, petroleros, gráficos, carne, ferroviarios). Comienza, también desde el inicio, a extenderse territorialmente en Bahía Blanca, La Plata, Córdoba, Rosario, entre otros lugares de Buenos Aires, y a desarrollarse en el ámbito juvenil, fundando la Tendencia Estudiantil Revolucionaria Socialista (TERS), que en 1972, cambia su nombre a Unión de Juventudes por el Socialismo (UJS), que perdura hasta la actualidad, con actividad en instituciones educativas y juveniles de todo el país, con una sistemática producción de boletines y volantes, y su propia publicación denominada La Caldera.

El primer número de Política Obrera sale a la calle en marzo de 1964, seguido de cinco números de manera bimestral/trimestral en formato de revista. El objetivo principal de esta publicación era sentar las bases políticas y programáticas para el desenvolvimiento de la nueva organización, que dedicó sus primeros números a la delimitación del resto de la izquierda, declarándose trotskista y defendiendo en sus textos la continuidad histórica de ese movimiento. Luego de estos primeros seis números salen otros seis con formato de revista/boletín, "una impresión de Rotaprint en hoja oficio doblada por la mitad con dos colores (rojo y negro) solamente en la tapa." (Kohn, 1999: 96), con una extensión de 32 páginas y periodicidad mensual, que comienza paulatinamente a penetrar en los conflictos del movimiento obrero.

Bajo el gobierno de Onganía y el fervor de las masas en resistencia, se desata una ola de huelgas en las que el PO tiene una importante intervención, y que se manifiesta en el incremento de sus publicaciones a pesar de su prohibición por la dictadura. El boletín, que en ese entonces era Política Obrera, comienza a salir cada 15 días dedicando la mayor 
parte de sus columnas a los conflictos en las fábricas y sus reivindicaciones. Para inmiscuirse entre los trabajadores, adopta un nuevo "lenguaje" más accesible, pero continúa con la transcripción de materiales teóricos, principalmente de Marx, Lenin y Trotsky. Por otro lado, además del boletín, el partido publicaba, en ese entonces, folletos en acontecimientos específicos, como la devaluación monetaria; y "Voz Obrera", una publicación de las listas sindicales, que era reproducida como boletín en algunas oportunidades.

Posteriormente, en sintonía con el crecimiento del partido, Política Obrera se convierte en periódico y comienza a salir, sistemáticamente, de manera semanal. Las ediciones de Política Obrera mejoran en calidad y se implementa la venta por suscripción. Sin embargo, la prohibición de esta publicación por la dictadura, hacía muy difícil la impresión del periódico que resultaba en un gran obstáculo al desarrollo y crecimiento del periódico y de la organización. En un principio, algunas imprentas trabajaban en forma clandestina, pero esto era cada vez era más peligroso y los precios incrementaron vertiginosamente. Ante la negación de las imprentas de ser allanadas o clausuradas y la necesidad de sostener regularmente la publicación, el equipo que trabajaba en la elaboración de Política Obrera comenzó a encargarse de la impresión de los alrededor de 1500 ejemplares que salían a la calle.

El avance que había tenido el periódico se vio frustrado por el acrecentamiento del control y la represión de la dictadura de 1976, tras la proscripción de Política Obrera y la prohibición de su periódico. La frecuencia de Política Obrera volvió a ser de una vez por mes, pero se sostuvo con regularidad, con el imperioso ingenio y camuflaje que exigía la clandestinidad. Para protección de los compañeros, el periódico comenzó a llamarse "Adelante" y para referirse a él le decían "Adela". Había un comité de redacción clandestino y parte del contenido era escrito desde Brasil y Europa, donde se encontraba la dirección del partido. La difusión era un desafío que encontró, durante esos años, diferentes formas de escabullirse del control y la represión del régimen dictatorial. Uno de los métodos de camuflaje para repartir el periódico consistía en envolver el periódico con la apariencia de paquetitos de 10 bolsas de residuos, donde en realidad sólo había una bolsa y adentro estaba el periódico. Una comisión de la organización se encargaba de poner el periódico en los paquetes de bolsas que eran selladas con una máquina automática y llevaban la leyenda "Bolsiplast". "Y eso permitía que circule... era todo un arte", decía Carlos Frigoli, responsable (rentado) de la biblioteca porteña, obrero mecánico despedido con 7 hijos y 40 años de militancia en el partido. Por su parte, para poder repartir los volantes en las fábricas y que no sean pisoteados si los tiraban al suelo, les hacían un agujero y le metían un alambre para dejarlos colgados en determinados lugares "y la gente iba y los agarraba de a uno, cada uno se llevaba su volante, no arrancaba todo... ese es un espíritu democrático antidictatorial de la población" (Entrevista Carlos Frigoli, 11/2014).

En 1982, Política Obrera decide intervenir en la nueva etapa política, participando en el proceso electoral, por lo que llaman a luchar por la legalidad y a construir un partido obrero. La campaña por este objetivo fue realizada sistemáticamente por los militantes y la difusión del periódico, que a partir de diciembre de ese año comenzó a llamarse Prensa Obrera, resultó fundamental para lograrlo. Finalmente, el PO consiguió la legalidad en 14 provincias. Concluida esta tarea, el partido se plantea un nuevo objetivo: "Vender 10 mil ejemplares de Prensa Obrera" (Prensa Obrera, 6/5/83, citada en Kohn, 1999: 101) Ya en el $\mathrm{N}^{\circ} 12$ se destacaba que la prensa era el instrumento más importante para el desarrollo del partido. 
Desde la vuelta a la democracia, la publicación de Prensa Obrera se sostuvo regularmente de manera semanal hasta la actualidad, así como una cantidad de publicaciones adicionales. El lugar de la cultura escrita en el PO ha sido muy extenso a lo largo de su historia y es un elemento fundante, constituyente y vital de toda su actividad política en la actualidad. Dentro de la vastedad que caracteriza a la producción escrita del partido actualmente destaca, primordialmente, Prensa Obrera que es el centro neurálgico a partir del cual gravitan casi la totalidad de las actividades de la organización y el trabajo militante de sus miembros. Esta publicación de aparición semanal y una tirada de 15.000 ejemplares, en 2007 alcanzó la edición número 1.000 y en 2018 la número 1500.

Según se desprende de las entrevistas y la observación etnográfica, el lugar protagónico otorgado a la prensa en el PO, responde, fundamentalmente, a la necesidad de intervenir en una realidad social y política particular a través de un posicionamiento y una orientación política que se hace por escrito. "Finalmente, eso es una prensa obrera: una toma de partido y una orientación en la contingencia, un documento inalienable que expresa cómo la lucha de clases va escribiendo la historia; la fuente donde establecer un balance respecto de la eficacia de la estrategia partidaria, de la solidez de un programa. Que se puede cotejar, porque está escrito"(Altamira, 03/05/2018). Asimismo, Prensa Obrera no es solamente el vector de un programa y de una estrategia política, sino también una "tribuna" a través de la cual se puede ejercer una influencia en la construcción política. A la vez que funciona como un elemento unificador del discurso y la acción partidaria, y se establece como centro neurálgico de la actividad militante, ya que es una herramienta de formación política por un lado, y por otro, es la herramienta privilegiada para acercar e incorporar nuevos miembros a la organización a través de la discusión de las caracterizaciones y las posiciones políticas partidarias que se desarrollan en el periódico, lo cual es el principal objetivo cotidiano de la militancia en un partido que se propone la toma del poder.

Al llegar los periódicos a cada provincia, regularmente el día establecido, se distribuyen por comités y éstos, a su vez, reparten la cantidad asignada a cada uno en los diferentes círculos (célula mínima de la organización), en proporción a un promedio de los periódicos "rendidos" en las últimas tres semanas, más un $10 \%$. Así cada militante obtiene una cantidad más o menos estable de periódicos que debe pasar a sus contactos durante la semana y ofrecerlos a otros nuevos. Las maneras de hacerlo son diversas y dependen de cada círculo, de a quién se quiere vender, dónde y cuándo.

Asimismo, en cada actividad que realiza el partido se ofrece la prensa. Una de ellas son las "mesitas de agitación" que en su mayoría tienen días y horarios preestablecidos (incrementando su frecuencia en campañas determinadas) como en la universidad o en la peatonal, o en las diferentes actividades que se realizan, ya sea pintar un mural, la presentación de un libro, una charla debate o un brindis de fin de año, entre muchísimas otras, donde se coloca una mesa con materiales donde invariablemente se venden periódicos y, dependiendo el caso, puede haber boletines, folletos, libros, remeras, etc.

Otra manera de vender el periódico es el "piqueteo" en las movilizaciones y actos, para lo cual se asignan compañeros a realizar esta tarea. Los militantes del PO utilizan la palabra "piquetear" como un verbo, y como un sustantivo "el piqueteo", para referirse a la actividad de ofrecer prensas (por ej., “¿quién va a piquetear en la marcha?” o “tenemos que reforzar el piqueteo"). A diferencia del "pasaje en mano" que refiere a la venta del periódico a "relaciones" o "contactos" (personas con las que se viene llevando a cabo una discusión política, potenciales militantes del partido), para lo cual los militantes van al encuentro de sus contactos en sus casas o lugares de trabajo donde les llevan el periódico. 
El primer acercamiento hacia nuevos contactos es, generalmente, a partir del "pasaje" de la prensa, y en caso de que la relación comience de otro modo, por ejemplo por compartir espacios asamblearios, se busca seguidamente pasarle el periódico. Y efectivamente, el pasaje de Prensa Obrera ha ganado muchas incorporaciones al partido y es por ello que la venta del periódico ocupa un rol primordial en la actividad militante.

\begin{abstract}
"Mucho se ha escrito sobre la prensa revolucionaria, y lo hicieron los grandes revolucionarios. Yo sólo quiero mostrar el rol que jugó Prensa Obrera en mi incorporación al PO y - a partir de esta experiencia, que bien puede ser la de varios compañeros - señalar la tremenda importancia que tiene el periódico de los militantes socialistas.

Me impactó el título de tapa "Por una alternativa política de la clase obrera". Bastó tan sólo un título para que comenzara a interesarme por los demás artículos. Así me incorporé de lleno a una actividad militante (Barraza, 12/07/2007)
\end{abstract}

En consecuencia, además del punto del temario específico en las reuniones semanales de círculo donde se evalúa y se rinden las prensas, el pasaje de la prensa es motivo de discusión en prácticamente todas las reuniones e instancias de encuentro generales de la organización. También es causal de reprobaciones y advertencias cuando los "objetivos" de pasajes de periódicos no se cumplen semanalmente, lo cual es lo que sucede más a menudo, como si esos objetivos fueran demasiado pretenciosos o estuvieran desfasados de la práctica real. Este ahínco en el arraigo en los principios esbozados en el ¿Qué hacer? escrito por Lenin en 1902, donde se insta a hacer del periódico una actividad central de la organización partidaria, se sostiene en el tiempo (no sin discusiones de por medio), a la vez que se incorporan cada vez más otros elementos y herramientas, como las que ofrece la virtualidad, aunque la prensa impresa tiene cada vez menos recepción, mientras se incrementan las visitas del sitio web de Prensa Obrera. Entre los cursos de formación que suele dictar el partido, uno de los que es considerados más importante es sobre el ¿Qué hacer?, que termina (generalmente en su tercera clase) debatiendo sobre el rol del periódico impreso.

A nivel general, el periódico semana a semana hace pública la posición del partido sobre los temas sociales de actualidad, que de manera ineludible contiene un señalamiento de cómo la clase trabajadora debe actuar en cada contexto. Es por ello que las "notas" que contiene Prensa Obrera no son únicamente una exposición sobre diversos temas, ni una cobertura de los conflictos sociales que escasamente figuran entre las columnas de los diarios oficiales, sino una intervención social en la realidad, en al menos dos sentidos relacionados: el primero de ellos es la intervención del periódico en sí mismo, como materialidad que suscita una serie de acciones, y la segunda, es la intervención potencial de un programa de acción, que consiste en una serie de acciones a llevar a cabo o un programa político a partir de la caracterización de tal o cual acontecimiento.

En concordancia con este método de intervención que se manifiesta semanalmente en la publicación oficial del PO a nivel nacional, cada expresión del partido hasta en el último rincón del país interviene ante las diversas situaciones con un posicionamiento político por escrito. Generalmente estas posiciones son "comunicados", que algunas veces se imprimen y se reparten en forma de volantes y otras veces circulan de manera virtual. La característica más relevante de estos comunicados es la inmediatez con la que se escriben y publican, y que responde a la necesidad de actuar sobre una realidad que se está desenvolviendo en ese momento y de la cual se participa activamente. Un caso ilustrativo de esta manera de operar, tomando sólo uno de los cuantiosos ejemplos que presencié durante el trabajo de campo, es un comunicado de Tribuna Docente Córdoba durante una 
movilización en repudio al acuerdo salarial fraudulento de la conducción del gremio docente con el gobierno provincial y a la represión policial que tuvo lugar ante la manifestación pacífica que exigía no cerrar el acuerdo. Mientras estos hechos estaban ocurriendo salió un comunicado de la agrupación. La manera de proceder fue una breve reunión de los miembros (en la misma concentración) donde se discutieron los lineamientos generales que debía contener el comunicado y la designación de uno de ellos para llevarlo a cabo, para lo cual se fue a un Cyber a pocos metros de donde se encontraba la concentración de manifestantes, redactó el comunicado y lo publicó inmediatamente; a los pocos minutos la posición de Tribuna había llegado a un sinnúmero de personas y medios de prensa.

Los comunicados particulares de las agrupaciones y el periódico se encuentran inmersos en una red enmarañada de sujetos, acciones y materialidades a partir de la cual se erigen. En ella, ambos se distinguen, es decir, contienen unas características determinadas que les otorgan su especificidad, pero se relacionan inherente y constitutivamente en, al menos, dos sentidos: por un parte, el periódico se conforma en gran parte de las notas locales, que le otorgan su carácter nacional y federativo; y, por otra parte, cada expresión del PO es una manifestación particular del partido en su conjunto, es decir, cada posición local específica responde, reproduce y legitima el posicionamiento político general del partido, que a su vez crea y constituye. "No es que en el periódico se sientan cuatro tipos y escriben, escriben, escriben, escriben y van y le dicen al partido lo que hay que hacer, sino que se junta de todos lados, es un ida y vuelta." (Entrevista a Eduardo Salas, 07/2014).

Además del periódico, el PO cuenta con una vasta producción escrita. Ahondar en detalles y explayarme en descripciones sería una labor interminable. Cada agrupación en cada lugar del país en los que está el PO tiene, de manera más o menos sistemática, su propia publicación, y cada círculo tiene también algún tipo de producción y divulgación de sus ideas y propuestas. Además del periódico, los boletines de agrupación y los comunicados, el partido también cuenta con una revista teórica, En Defensa del Marxismo, de aparición irregular pero sostenida en el tiempo, y libros impresos que, por lo general, son escritos por ciertos dirigentes o intelectuales militantes, y tratan sobre diversos temas desde un punto de vista marxista. Algunos de ellos son editados por la editorial del partido y otros encargados a otras editoriales, el partido los vende en sus locales y mesas de materiales. $\mathrm{Y}$, aunque no son de consumo interno sino para el público en general, se suele fomentar su lectura entre los militantes para su formación teórica, histórica, económica y/o política, ya que esta formación intelectual se considera útil para el desempeño del trabajo de militancia y de la organización en su conjunto. En consecuencia, la vida de los militantes del Partido Obrero está empapada de cultura escrita y la práctica de lectura es muy asidua. La lectura de la prensa partidaria ocupa un lugar fundamental en la cotidianeidad de cualquier militante del PO, que se manifiesta -entre otras cosas- en la construcción discursiva de la comunidad en su conjunto.

Dentro del universo impreso del Partido Obrero, la literatura, como la definiremos a continuación, ocupa un lugar marginal y esto se debe, en parte, a las concepciones sobre el arte en general que se tiene hacia dentro de esta comunidad.

\section{Literatura y política, en el trabajo de campo}

En primer lugar, es necesario decir que no existen entre la literatura y el resto de las esferas de lo social unos márgenes finitos que nos permitan definir y delimitar a la 
literatura como un espacio determinado, sino que estos límites se presentan siempre difusos y diseminados. La especificidad de la literatura, se establece, entonces, únicamente en el plano teórico a los fines de la investigación, a partir de los datos obtenidos en el trabajo de campo. Dicha especificidad se caracterizaría por la preeminencia del elemento estético -como un modo de relación con los objetos artísticosy se circunscribe en oposición a la producción escrita partidaria (periódicos, boletines, volantes, entre otros). Aun así, dentro del Partido Obrero "no existen grandes murallas chinas entre la literatura y la cultura escrita" (Entrevista Pablo Rieznik, 11/2014), puesto que el vasto repertorio de lo escrito alcanza a los diseminados márgenes y cualquier intento de clasificación taxativa sería arbitraria y reduccionista; un ejemplo paradigmático de esto lo constituyen los libros publicados por el PO, en su gran mayoría de historia, economía política y análisis social, pero también crónicas literarias y libros de poesía que siendo objetos artísticos son también una intervención política, como vamos a ver.

Así definida, la literatura, siempre parte de la producción textual en su conjunto, ocupa en el PO un lugar secundario, cuantitativa y cualitativamente, en relación a la producción escrita partidaria, esto es, el periódico semanal Prensa Obra que es para los propios militantes "el cerebro de la organización", los boletines sindicales, folletos, volantes y una enorme cantidad de formatos de publicación impresos y digitales. Esto se debe, fundamentalmente, al tipo de organización de la que se trata -un partido político-, y, en consecuencia, a las actividades que desarrolla; pero también a las concepciones sobre la literatura y el arte en general que circulan dentro del PO. Sin embargo, aunque en un porcentaje menor dentro de la cultura escrita, la literatura instituye una esfera de la vida del Partido Obrero y a ella nos dedicaremos a continuación.

\section{Trotskismo y literatura}

Referirme a mi objeto de investigación en términos de "literatura y política" me propició unas cuantas arengas sobre política trotskista y la relación del PO, como partido que autoadscribe trotskista, con la literatura y el arte en general,con una marcada regularidad discursiva. En consecuencia, y puesto que la política del partido respecto de la literatura, de alguna manera u otra, es un condicionante del lugar que esta última ocupa en la organización, resulta menester hacer una breve caracterización de dicha relación, para poder después analizar la literatura en la actualidad, su presencia y circulación en el Partido Obrero.

Históricamente, la literatura ha sido objeto de diversas tendencias orientadas a hacer de ésta un medio trascendente para un fin último, estableciendo de este modo distintas sujeciones y coacciones a la creación artística literaria. Algunas veces estas tendencias han sido "voluntad" individual de algunxs escritores (atravesadxs por las predisposiciones de su época) como en el caso del "compromiso" social; pero otras, las tendencias han sido disposiciones políticas que se han impuesto sobre las decisiones individuales de cada escritorx, llegando incluso a convertirse en política de Estado, como en agosto de 1934, cuando el Congreso de Escritores Soviéticos promulgaba el "realismo socialista" como doctrina oficial. Redactada por Stalin y Gorki, "la doctrina establecía que el deber del escritor era «conocer la vida, para saber representarla fielmente en las obras artísticas (...) como realidad en su desarrollo revolucionario»" (Eagleton 2013:100). Sentenciando a lxs escritores a atenerse a tales requisitos, la doctrina exhortaba a la literatura a ser "tendenciosa" y "proclive" a la "revolución proletaria". En el otro bando y co-contemporáneamente, el régimen fascista alemán dictaminaba lo que 
podía y debía ser dicho y lo que no, prohibiendo a lxs escritores que se pronunciaran por la libertad de creación y convirtiendo a lxs que quedaron con vida en lacayos del régimen. En 1938, momento en el que el mundo se encontraba atrapado por estos dos insaciables totalitarismos, desde su exilio en México, Trotsky se reunió con André Bretón y Diego Rivera, con el propósito de crear la Federación Internacional de Artistas Revolucionarios ante la necesidad de ofrecer una alternativa política a la intelectualidad de izquierda desencantada con el estalinismo y las olas represivas desatadas en Moscú. Para el exiliado -que de chico había anhelado ser escritor aunque renunció a su sueño en pos de la labor revolucionaria-, bajo ningún concepto había derecho de imponer condiciones a la libertad artística, y ello era innegociable aun ante la excusa de la necesidad política o histórica. De este modo, Trotsky se opuso con ahínco al régimen estalinista que había silenciado por la fuerza, exiliado y asesinado a una cuantía de escritores que se resistían a adoptar los condicionamientos unívocos formulados por el gobierno, convirtiendo al arte soviético en una pantomima, que el líder del Ejército Rojo caracterizó como decadente y repugnante.

Para Trotsky, el arte no debía admitir ninguna restricción sino que debía atenerse únicamente a sus propias reglas y sólo a ellas, puesto que la libertad en el arte era incondicional y sagrada. En el Manifiesto redactado llamando a la creación de la Federación, junto a Bretón y Rivera, se pronunciaron a favor de un arte independiente en oposición al yugo utilitarista y panfletario que caracterizaba a la cultura alemana y de la URSS, donde lxs artistas eran funcionarios vigilados que sólo tenían la posibilidad de alabar al régimen y adular a los grandes jefes, bajo la consigna de la unanimidad ideológica ante el enemigo.

Adscribiendo a esta concepción trotskista sobre el arte, el Partido Obrero sostiene como política la plena independencia y la libertad de creación artística.

“En 1974 decidí ir ligándome al PO (que por entonces era Política Obrera) por razones estrictamente políticas pero también por razones -llamémosle"ideológicas": era la única corriente en la cual no cabían los populismos, en la cual no cabía la censura respecto de las artes y de la literatura... y la vida me había ido preparando para buscar ese tipo de cosas. Mi lugar de libertad, era la literatura y el arte. Siempre me fascinó todo lo relacionado con el arte, entonces que a mí me dijeran que no valía la pena leer a Borges porque era un reaccionario, que fulanito, que menganito, no. En cambio la postura de la entonces Política Obrera, como trotskista, era la que tomaron los surrealistas: toda libertad en el arte. Entonces a mí me gustaba tanto la música... por ejemplo, en el PC escuchar música atonal o experimental era, para ellos, cosa de pequeñoburgueses, ni que hablar para los Montoneros, y en parte también para el PRT-ERP. A mí no me interesaba nada de eso, amén de que no me interesaban las posturas políticas. Entonces fui entendiendo -pero entendiendo realmente, no entendiendo en los libros- que había una gran relación entre esas posturas ante el arte y la literatura y las posturas políticas; porque si vas a censurar, o limitar incluso, qué es decible y qué no es decible, qué debe mostrarse y qué no: ya eso es una postura política también. Y lo otro que era fundamental es que junto a esa libertad también tenía que haber una calidad. Porque el hecho de escribir para "el pueblo" (entre comillas) a muchos los eximía de escribir bien, por decirlo de alguna forma. Eso tampoco me interesaba, porque a mí me gusta la literatura como arte no como propaganda política. En ese aspecto, ya tenía claro ese interés y con el PO coincidimos totalmente en que una cosa es la propaganda política y otra cosa es la literatura y el arte." (Entrevista a Eugenia Cabral, 2015) 
Podría decirse, entonces, que la relación entre la política y la literatura en el PO no es en el campo de la utilización práctica, instrumental, cognoscitiva, de la literatura para un fin más allá de sí misma y sus propias exigencias, a diferencia de lo acontecido en los Partidos Comunistas, como es el caso exuberante de la doctrina del realismo socialista. Ya que, el Partido Obrero defiende la libertad de creación artística y su independencia de los marcos partidarios, puesto que se considera que si el partido establece una suerte de orientación -es decir que el partido actúe de árbitro con una visión utilitarista- sobre la creación, se vulnera la libertad que la literatura "necesita" para considerarse verdaderamente artística, puediendo afectar también su calidad artística. La política del partido es, por ello, para con la literatura la "total libertad", que implica que lxs artistas creen y desarrollen las obras culturales como cada uno guste o considere conveniente. Es decir que el partido, en tanto partido, no produce literatura, ni promociona o fomenta cierto tipo de lectura en detrimento de otra. De hecho, no hay entre lxs militantes del PO una apreciación particular por lxs "escritores militantes".

"Mirá, yo no creo en el escritor militante, o sea que tenga que escribir para; las ideas no se defienden de esa manera. Por supuesto que hay escritores que han podido... hay toda una cantidad de novelas sociales que reflejan y denuncian la explotación, y que han servido como un arma, pero no creo en la literatura como propagando política. Además Borges no era precisamente un militante y nadie puede negar que es uno de los mejores escritores que pisó la Tierra y que su aporte a la humanidad es inmenso. Y lo mismo Varga Llosas, que tiene un análisis tan fino de cualquier realidad y de todo lo que es la luchas de clases, y que finalmente -en mi opinión- a pesar de lo reaccionario que dice ser o que son sus planteos, siempre los personajes rescatables y buenos de sus novelas son los de izquierda y son los que luchan" (Entrevista a Maura, 2014).

Dejando a un lado la literatura como propaganda política, el partido o, más precisamente, algunxs escritores del partido que entrevisté durante el trabajo de campo, identifican, al menos, tres tipos de relaciones, más bien indirectas, entre la literatura y la política:

- La literatura puede ser un gesto político en la forma misma de la escritura; como la literatura rupturista de vanguardia, que representa un hecho político de por sí, al desafiar el orden establecido, en las relaciones textuales.

- La literatura tiene posibilidades de crear un mundo total, y en ese mundo se pueden ordenar las ideas respecto al mundo real estableciendo, por ejemplo, relaciones políticas entre los personajes que le permiten a lxs lectores crear vínculos entre las relaciones en el texto literario que podrían tener validez en el mundo en el que vivimos.

- La literatura actúa efectivamente sobre el plano de lo real al crear en lxs lectores reflexiones sobre diferentes cuestiones. Por ejemplo, en el caso de la poesía (o al menos cierta poesía), esta tendría el efecto de despertar y poner en vigilia, debido a que es un tipo de lenguaje con una gran concentración de significados afectivos e intelectuales que requieren una especial atención para su entendimiento y aprehensión, iluminando alguna zona del pensamiento, provocando cambios, generando preguntas. 
"Yo creo que una persona que lee poesía vanguardista no tiene por qué tener una relación con la política, pero sí tiene una relación con la literatura que abre la mente de esa persona, porque necesariamente vos tenés que construir, en ese poema que al principio te parece incomprensible, un mundo, pero para hacerlo tenés que salir de lo establecido y de lo que te enseñaron (...) Pero la relación entre la literatura y la política tiene un límite. La política se comprende a través de la experiencia práctica de la construcción de un partido y planteos concretos; es decir, la literatura puede ser una vía y un camino para llegar a ciertas conclusiones, pero el mundo no se cambia con el arte" (Entrevista a Diego Rojas, 2014).

Para lxs militantes del PO, la lectura y/o escritura literaria no es considerada parte de la actividad política. La militancia de lxs escritores del partido no se realiza en el plano de las obras artísticas, sino en la organización política, ya sea como "trabajadores de la cultura" o en otros ámbitos. Es decir que, en lugar de "escritor militante" -emblema de la segunda mitad del siglo XX-, en el PO asistimos a la militancia de lxs escritores, divorciada de la valoración y la producción estética.

\begin{abstract}
"Esa es la relación más rica entre el arte y la política, cuando vos como artista tomás una posición aunque esa posición no se transparente en tu producción artística, porque de otra manera se pueden dar casos de un autor que escriba sus novelas, sus poemas, sobre un conflicto y considere eso como su militancia, no está construyendo nada; está vistiendo de literario un panfleto, pero sin construir nada alrededor de esa posición. Yo prefiero todo lo contrario, un artista que haga su arte como quiera y que como artista tome una posición ante determinados hechos políticos." (Entrevista a Franco Boczkowski, 2014)
\end{abstract}

En el terreno de lxs trabajadores del arte, la lucha particular del PO está orientada en contra de la tendencia privatista de la cultura y de las concepciones del arte como mera mercancía y de la cultura como negocio; a erradicar la injerencia del Estado y de la Iglesia en la creación artística, tanto a través de la censura y como del control ideológico; por el aumento de presupuesto para la cultura y el arte; por el derecho de la población a acceder a ella y por una ley de pensión universal para artistas.

Sin embargo, estas reivindicaciones para la literatura y el arte están articuladas, enmarcadas, atravesadas y fundadas en un programa político general que busca garantizar la plena libertad artística promulgada, a partir de la abolición del capitalismo, su sistema de mercado y los totalitarismos a los que éste ha dado lugar. En consecuencia, según lo autoperciben los miembros de esta comunidad, el Partido Obrero lucha en contra de la explotación y opresión capitalista, proclamando una transformación social en donde la dominación de clases y las propias clases sociales en sí sean suprimidas a partir de la destrucción del régimen de propiedad privada de la tierra y los medios de producción, dando lugar así a la emancipación del conjunto de la humanidad.

"He aquí lo que queremos:

La independencia del arte, por la revolución; La revolución, por la liberación definitiva del arte.” (Bretón, Rivera, Trotsky, 1938)

\title{
La literatura en el PO y viceversa...
}

Ahora bien, como se puede ver, aunque secundario en relación a la producción escrita partidaria, la literatura sí ocupa un lugar en el PO, y circula de diversas maneras. En 
primer lugar, la práctica de lectura es generalizada y asidua. La disciplina de lectura, "que es una disciplina no impuesta, sino que va surgiendo a medida que surge la convicción política" (Entrevista a Eugenia Cabral 10/2014), es una regularidad en lxs militantes del PO, que se adquiere, en primer lugar, a partir de la lectura del periódico y otros medios de información partidarios o no, pero que al convertirse en un hábito alcanza, en su gran mayoría, a otras formas escritas, como la propiamente literaria. Sí como dice Roger Chartier (2006), es posible distinguir prácticas propias en cada comunidad de lectores, en el PO nos encontramos con una práctica de lectura muy marcada, que constituye un hábito militante que es promovido ávidamente en el partido como el principal instrumento de formación política, extendiéndose hasta alcanzar a la lectura específicamente literaria. Ello se materializa en la presencia de literatura en bibliotecas, en los stands de materiales, en las jornadas literarias, en las críticas de libros en Prensa Obrera y en En Defensa del Marxismo, así también como en la presencia de numerosxs escritores en el partido. En la totalidad de hogares de militantes del partido que visité en mi trabajo de campo, los libros eran parte constitutiva del paisaje hogareño; desde estanterías y bibliotecas hasta paredes enteras, estaban en el living, en la pieza, en la mesita de luz o coloreando algún rincón; y los libros ibas desde economía política hasta poesía clásica. La práctica de lectura, entonces, no se circunscribe a la literatura política o partidaria sino que trasciende esos difusos márgenes para abarcar todas las expresiones de la escritura. En ese sentido, política y literatura encuentran una continuidad y complementariedad en la práctica de lectura.

"En mi experiencia personal, pero eso sí que es mi experiencia, cuando empecé a militar es cuando empecé a descubrir (también por la edad) lo que era la literatura y me empezó a gustar y poder verla de otra manera también... Vargas Llosa, Cortázar, particularmente ellos dos, y la poesía. Estaba muy ligado a la libertad." (Entrevista a Maura, 11/2014)

En segundo lugar, la relación literatura y política está dada por la presencia de escritores dentro de la organización, que de una manera u otra acercan la literatura hacia el partido, ya sea organizando mesas de "literatura y política" en actividades partidarias o compartiendo sus producciones con sus amistades dentro del partido, publicando en sus redes sociales o haciendo críticas literarias en los medios partidarios. En Córdoba, al igual que en otros lugares del país, hay escritores que son militantes activos del partido, como es el caso de Eugenia Cabral o Franco Boczkowski; pero hasta el momento de hacer mi trabajo de campo no se había conformado una organización propiamente de escritores como es el caso de Buenos Aires, donde lxs escritores que ya se encontraban nucleadxs en el Frente de Artistas del Partido Obrero, conformaron la agrupación Tinta Roja, para abordar las problemáticas específicas de lxs escritores como trabajadores de la cultura.

Otra forma de circulación de la literatura en el partido son las críticas de libros que ocasionalmente aparecen en Prensa Obrera o en En Defensa del Marxismo y en algunas actividades culturales, donde la literatura es una de la expresiones artísticas que tienen lugar en ellas, como suele ocurrir en los "Picnic" de fin de año, como el que se realizó en diciembre del 2014 en Córdoba, donde hubo una mesas, llamaba "Literatura y política", en la que participaron poetas de la ciudad, que habían sido invitadxs a leer sus textos. Conformaron la mesa, escritores de larga trayectoria como Ceferino Lisboa, y otros más jóvenes como Guillermo Bauden, Ávalo Colaso y Gerardo Pacheta y Fabio Martínez (que llegó tarde así que no pudo participar en la mesa); y del Partido Obrero, Eugenia Cabral y Franco Boczkowski. 


\begin{abstract}
"Por ahí cuando uno invita a estas actividades a los escritores se manifiesta un prejuicio, como lo organiza el PO y es una actividad de "literatura y política" algún escritor piensa "no, yo no escribo sobre política", y es una postura errónea, totalmente equivocada, porque la libertad para escribir sobre lo que uno quiera hay que defenderla en toda instancia. Cuando hablamos nosotros de "literatura y política" no nos referimos sobre qué escribir sino sobre qué papel podríamos jugar nosotros, los escritores, los trabajadores de la cultura, en una situación política, por eso se llama "Literatura y política" la mesa que organizamos en el picnic; no para regimentar la actividad de escritura. Nada más ajeno a nosotros que la regimentación de la actividad del escritor. De hecho nosotros, los militantes del PO, yo considero que tenemos más libertad para escribir sobre algo que no tenga que ver con la política, porque como la política es parte de nuestra actividad diaria, de nuestro trabajo en la vida (serio y disciplinado, por eso somos militantes), en la literatura no es necesario que hablemos de política, no es necesario que manifestemos nuestras posiciones, nuestra ideología, porque lo hacemos constantemente en nuestro trabajo de militancia" (Entrevista a F. B., 10/2014)
\end{abstract}

Después de que cada unx leyera poemas de su propia autoría, finalizó la primera ronda de lectura y Franco comentó que la intención de que la mesa se llamara "literatura y política" estaba ligada a la posibilidad de que, además de compartir las producciones literarias, se pueda reflexionar y discutir acerca de la situación política y la posible intervención de los escritores; proponiendo conformar desde los trabajadores de la cultura, comités de apoyo al Frente de Izquierda. Luego leyó un poema, y la ronda volvió a comenzar, hubo algunos comentarios en respuesta a la propuesta de Franco pero la discusión no prosperó mucho más. Finalizada la segunda ronda, la mesa concluyó con aplausos.

Así como la literatura influye, indirectamente, en la política, creando reflexiones o mundos totales, como afirma Diego Rojas a partir de su experiencia: "mis primeras inquietudes políticas vinieron de la literatura" (Entrevista 11/2014), también es cierto lo contrario, es decir, que la política, en este caso en el PO, influye en las producciones artísticas. Si bien no lo hace de manera volitiva, ni lineal ni necesariamente, ya que como vimos no hay un política destinada a las producciones artísticas, existen huellas, al menos en algunos de los textos de escritores del partido, a partir de las cuales podemos inferir que la política es una actividad sustancial en la vida de estos sujetos, que los atraviesa y constituye integralmente. No se trata de una tendencia teleológica de los escritores a crear conclusiones políticas en los lectores a través de sus textos; sino que pareciera tratarse más bien de huellas del medio en el que se desenvuelven los sujetos, que se manifiestan en el lenguaje y la "jerga" militante. El siguiente poema de Franco, publicados el año 2013 en el libro Razones Personales, podría ser un ejemplo de ello:

\author{
Transición \\ No fue tragedia la primera, ni sería \\ farsa la segunda vez que nos encontremos, \\ nosotros mismos o distintos, o este martes \\ negro que no es y hace años se prolonga \\ y no acaba ni con Grecia, ni con Francia, ni Alemania, \\ ni con nosotros acaba, esta vez tampoco; \\ ni el tiempo y el espacio nos acaban. \\ No hay heroísmo en abandonar el conflicto \\ y evitar dar la pelea. Son éstas
}




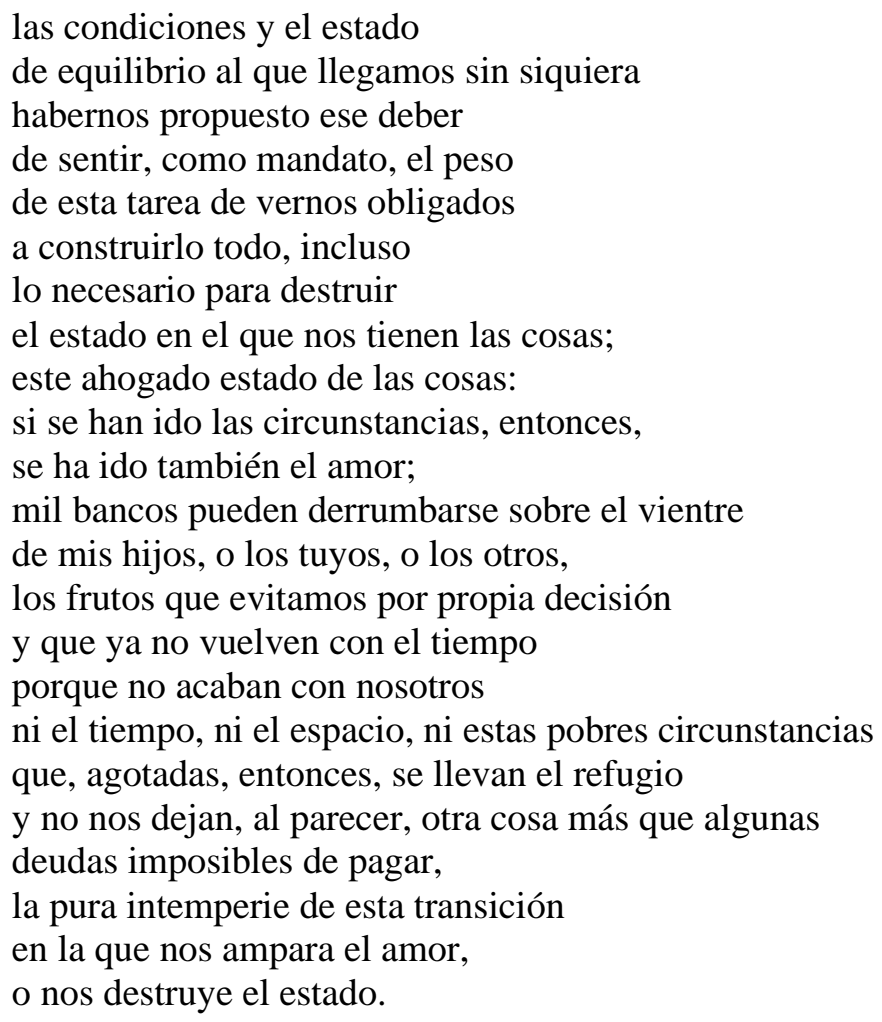

En este poema, y en muchos otros de los que componen el libro mencionado, publicado por la editorial independiente cordobesa "nudista", encuentro en Franco (al igual que en otros poetas militantes del PO), una huella de lectura que me sugiere -a nivel absolutamente personal, como la interpretación literaria lo es- una marca de pertenencia al Partido Obrero atravesada indudablemente por la lectura cotidiana de Prensa Obrera. Ello, sin embargo, no es algo que deduzca de las conversaciones con el autor, que aun habiendo reconocido la impronta que la lectura del periódico partidario pueda tener en su vida y por ello en su producción artística, afirma que sus poemas no son políticos sino "poemas de amor".

\section{"Mariano Ferreyra, un mundo aparte"}

"Leí un poema tuyo, Mariano, que escribiste para algún amor, donde hablás de una mirada que es mucho más que una mirada. Hoy le escribo a tu mirada que también es más que una mirada: es el cuerpo de los que pelean cada día por un mundo mejor.

De los que te cantan, te flamean, te duelen, te luchan".

Mariano, Daniel Mecca, en Poesía por Mariano Ferreyra.

El 20 de octubre de 2010, Mariano Ferreyra, joven de 23 años, militante del Partido Obrero, fue asesinado en una manifestación sindical de los trabajadores tercerizados del ferrocarril. Durante la protesta, una patota de la Unión Ferroviaria atacó a los manifestantes y una bala de plomo hirió de muerte a Mariano. Este crimen, generó una

\footnotetext{
${ }^{2}$ Así se refirió Eduardo Salas cuando lo entrevisté en septiembre de 2014, para referirse al caso de Mariano Ferreyra y la conmoción que había provocado, volcándose en producciones artísticas.
} 
profunda sensibilidad en todo el pueblo argentino, que se manifestó inmediatamente después del asesinato y al día siguiente pidiendo justicia por Mariano y que siguió movilizando hasta el encarcelamiento de Pedraza, entonces secretario general del sindicato de Ferroviarios. Esa sensibilidad suscitada por el crimen, se manifestó también entre lxs artistas allegadxs al partido, dando lugar a un gigantesco repertorio de expresiones culturales a partir de la muerte de Mariano. En este marco, se publicó en Córdoba, en el año 2013, el libro Poesía por Mariano Ferreyra, como resultado de una iniciativa de la poeta cordobesa Eugenia Cabral que el Partido Obrero llevó adelante. El libro comenzó con una convocatoria abierta para escribir poesía en torno al crimen de Mariano, que se realizó con el objetivo de poder canalizar la conmoción y sensibilidad artística que el caso de Mariano Ferreyra había provocado. La idea en un principio era juntar algunos poemas y organizar una mesa de lectura; pero al ser tanto el material que se obtuvo de la convocatoria, el partido se dio la tarea de publicar un libro y todos los poemas, que llegaron de diferentes lugares del país se publicaron sin censuras.

El libro Poesía por Marino Ferreyra, al igual que las diversas expresiones artísticas que tuvieron lugar a partir de la conmoción suscitada por el crimen de Mariano, son parte activa y constituyente de la movilización política desatada por el asesinato del joven. En ese sentido, nos encontramos aquí ante una relación entre la literatura y la política en ambos sentidos. Es decir, un hecho político, como es el caso de Mariano Ferreyra, genera una sensibilidad que se vuelca hacia el arte: la música, la pintura, el teatro, la poesía; y ese arte, a su vez, forma parte de una movilización popular y política que se traduce en la realidad; por ejemplo, en este caso, la consecuencia más indiscutible es el encarcelamiento de Pedraza. Y esto surge, no a partir de la premeditación del partido, sino de manera voluntaria por parte de cada escritorx, de cada poeta, que es sensible a la realidad y que un acontecimiento como el de Mariano le despierta la necesidad de escribir sobre el hecho y esa escritura puede (no debe) contribuir indirectamente, de una u otra manera, a la acción colectiva..

\footnotetext{
"Las imágenes duran pocos segundos. A lo sumo ocho. No más. Es un lapso suficiente para registrar las fatalidades de la violencia política en la Argentina de hoy. La cámara enfoca el interior de una ambulancia. Un joven de barba rala y pelo crespo parece inconsciente. Tiene los ojos entrecerrados y se encuentra acostado sobre otro cuerpo. Está pálido. Lleva puesta una remera gris levantada a la altura del abdomen, región donde se advierte un pequeño orificio, una herida que no sangra. El joven de pelo crespo toma aire y, al hacerlo, levanta un poco el mentón, mueve la garganta. Sus labios no se cierran, dejan ver los dientes en un gesto de cansancio. Vuelve a tomar aire, lo hace con dificultad. A su lado hay otro muchacho de pelo claro y anteojos que lo sostiene desde el cuello a la vez que le pega unas palmadas en la mejilla. "Abrí los ojos -le dice-. Mariano, mirame". El muchacho de anteojos acerca su cara a la del joven de los ojos entrecerrados e insiste: "Reponete, por favor, dale". Desde afuera, apuran al chofer: "¡ilevate al pibe, loco!”. Se cierra la puerta de la ambulancia. La cámara deja de filmar" (Rojas, 2011).
}

Diego Rojas vive en Buenos Aires, es periodista y militante del Partido Obrero. A los pocos meses de cometido el crimen político que terminó con la vida del joven militante del partido, Diego publicó un libro titulado ¿Quién mató a Mariano Ferreyra? fruto de una investigación sobre el hecho y los vínculos entre la cúpula de los gremios y el gobierno nacional. El texto reconstruye los acontecimientos en una crónica literaria, a la vez que realiza un retrato íntimo de Mariano, a partir de los relatos de sus parientes, amigxs y compañerxs de militancia. 


\begin{abstract}
"El caso de Mariano influenció en mi vida en todo sentido. Significó un viraje en la forma de ejercer el oficio y por lo tanto en mi vida en términos laborales, y por otro lado en un mayor compromiso, o un reencuentro pero de manera diferente, con el Partido Obrero. Si bien siempre fui del PO, había dejado de militar activamente en el 2004 y mi relación con el partido era más laxa; ahora creo que tengo un compromiso más fuerte, incluso más fuerte que cuando militaba, sobre todo por los efectos del libro; hubo gente que leyó el libro de Ferreyra y empezó o volvió a militar en el partido, es un efecto muy potente y para mí muy gratificante." (Entrevista a Diego Rojas, 11/2014)
\end{abstract}

La cita de Diego Rojas resulta ilustrativa. A partir del libro de su autoría, hubo gente que empezó o volvió a militar en el Partido Obrero. Claro que esto no se debe únicamente a una cuestión estética, sino que tiene que ver con posiciones políticas que se revelan en el libro, tanto en lo que refiere al partido como al accionar de la burocracia en complicidad con el gobierno nacional. Sin embargo, el libro de Rojas es un hecho concreto en el que literatura y política van de la mano, y un ejemplo elocuente de los alcances de la literatura como haz de efectos y potencialidades que trascienden la materialidad del libro.

Como hemos visto hasta aquí, la concepción de literatura (como creación artística independiente de los regímenes políticos y las doctrinas partidarias) atraviesa la relación literatura/política en múltiples sentidos. Por un lado, dicha concepción condiciona o facilita el acceso de determinados sujetos a la comunidad, como es el caso de Eugenia Cabral que decidió ingresar en el Partido Obrero por su política hacia la literatura y el arte en general. Por otro lado, esa misma concepción de independencia artística le confiere a la literatura un lugar marginal en el partido con respecto a la producción textual de propaganda partidaria y condiciona el lugar de los artistas dentro del partido, que es el de militantes al igual que otrxs, con la particularidad de que, en algunos casos, desarrollan su militancia como "trabajadores de la cultura". Esto último no quita que un escritor/a decida escribir sobre algún asunto social o político y contribuir, de este modo, a cierta consecuencia política, como es el caso de Diego Rojas, pero esto es iniciativa propia de cada artista. Por otra parte, la lectura sistemática del periódico y la escritura de comunicados o boletines, le confiere a los sujetos de esta comunidad partidaria ciertas marcas discursivas que influyen en sus creaciones artísticas.

\title{
Reflexiones finales
}

La hipótesis planteadas al comienzo de esta investigación, concerniente a la antropología como forma de construcción de conocimiento y acercamiento al mundo, estaba vinculada al desafío teórico y práctico de desarrollar una investigación antropológica, etnográfica, en el marco de un tópico del pensamiento contemporáneo venido, primordialmente, de la filosofía y las humanidades clásicas, como es el vínculo entre la literatura y política. Pensar desde la antropología el entre de la literatura y la política, como expresión del "afuera" del lenguaje, resultaba y resulta un desafío posible, dadas las manifestaciones, visibles y no visibles, de este aspecto de lo social, que hacen que esta relación pueda ser problematizada y estudiada antropológicamente a partir del anclaje en un referente empírico específico, dando cuenta de los múltiple procesos, sujetos y materialidades que la constituyen. La constitución política de una comunidad con su propia definición ("principios", "programa", "objetivos", etc.) y el lugar que ocupa en el sistema de relaciones sociales de mayor alcance, en la que se encuentra inserta, fundan las marcaciones/demarcaciones de pertenencia común de los sujetos de una comunidad, así 
como las relaciones de la comunidad en su conjunto con diversos aspecto de lo social, como la literatura.

En el caso del Partido Obrero, la cultura escrita ocupa un lugar clave en el desarrollo político estratégico y en la práctica militante cotidiana del Partido Obrero y sus miembros, respectivamente. En ese marco inmediato del que es parte indefectible, la literatura se desenvuelve en continuidad y complementariedad con la cultura escrita tomada en su conjunto, y representa, de este modo, aunque menor y prácticamente insignificante en relación al resto de la producción escrita, un aspecto de la vida social de los sujetos de este partido político.

En síntesis, tanto los procesos sociohistóricos en los que se desenvuelve e interviene una comunidad, como las prácticas y concepciones de los sujetos que la conforman, inciden, fundan y constituyen incesantemente las relaciones entre la literatura y la política que se desenvuelven en los marcos de (auto)referencia y (co)pertenencia de una comunidad dada. Con lo cual, cada comunidad, cada partido en este caso, adquiere una especificidad propia, local e histórica, propicia de ser abordada desde la antropología.

\section{Bibliografía}

Altamira, Jorge (2018) Prensa Obrera, $\mathrm{N}^{\circ}$ 1500, 03/05/2018, disponible en: https://prensaobrera.com/partido/prensa-obrera-1500/

Angenot, Marc (2010). Interdiscursividades. De hegemonías y discursos. Córdoba: Editorial UNC.

Barraza, Pepe (2007) Prensa Obrera, 12/07/2007, disponible en: https://prensaobrera.com/partido/prensa-obrera-la-mejor-arma-para-un-revolucionario/

Burke, Peter (1993) Formas de hacer historia. Madrid: Alianza.

Boczkowski, Franco (2013) Razones personales. Nudista. Córdoba.

Breton, André; Rivera, Diego; Trotski, León [1938] "Manifiesto por un arte revolucionario independiente", México. Disponible en: http://sgpwe.izt.uam.mx/files/users/uami/nivon/BRETON_manifiestopdf.pdf

Cabral, Eugenia; y varios (2013) Poesía por Mariano Ferreyra. Babel Editorial. Córdoba.

Chartier, Roger (2006) Inscribir y borrar: cultura escrita y literatura (siglos XI-XVIII). Buenos Aires: Katz.

Darnton, Robert (2003) Edición y subversión. Literatura clandestina en el Antiguo Régimen. Turner. Fondo de Cultura Económica.

Debray, Régis (2001) Introducción a la mediología. Barcelona: Paidós.

Goody, Jack (1996.) Cultura escrita en sociedades tradicionales. Barcelona, Gedisa.

Kohn, Laura (1999) "Historia de Política Obrera". En Defensa del Marxismo, No 24. Disponible online: https://revistaedm.com/edm/24/historia-de-politica-obrera/

Lenin, Vladimir Ilichi (2010) ¿Qué hacer? Colección Claves para el Socialismo. Ministerio del Poder Poder Popular para la Comunicación y la Información. Caracas. Disponible en: https://www.marxists.org/espanol/lenin/obras/1900s/quehacer/que_hacer.pdf

Martínez Mazzola, Ricardo H. (2005) El papel de la prensa en la formación del socialismo en la Argentina (1890-1912). VII Congreso Nacional de Ciencia Política, SAAPUniversidad Católica de Córdoba.

Rojas, Diego (2011). ¿Quién mató a Mariano Ferreyra?. Grupo editorial Norma. Buenos Aires. 